\title{
Perception of Residents, Community Participation and Support for Tourism Development in the Old Town Muang Songkhla, Thailand
}

\author{
Wilawan Jansri \\ Faculty of Economics and Business Administration, Thaksin University, Muang Songkhla, Thailand \\ wilawan@scholar.tsu.ac.th
}

\begin{abstract}
It is well known that community participation is the foundation for sustainable tourism development. The research focuses on the effects of perceptions among residents on community participation and explores the impacts of community participation on Support for Tourism Development in the Old Town Muang Songkhla, Thailand. The study employed a systematic random sampling method using a questionnaire to accessed resident perceptions of the Old Town Muang Songkhla, Thailand. The Partial Least Squares Structural Equation Modelling (PLS-SEM) techniques were applied to analyze the data. The results from 222 surveys revealed that community participation is influenced by both positive perceptions and negative perception of the residents. Moreover, the finding supports the effect of community participation on Support for Tourism Development. It is a clear statement that the role of the residence is important to support tourism development and maintain its strong growth. This research provokes reflections on community participation theory and management practices in the Thailand context.
\end{abstract}

KEYWORDS: perception of residents, community participation, support for tourism development

\section{Introduction}

In the past, Thailand has realized the importance of tourism development to help drive the country's economy. Such development relies on the advantages of the abundance of tourism resources and the diversity of cultures, including Thai being an important selling point in promoting the tourism market for a long time. In order for Thailand to have a clear development direction in line with potential and new development opportunities that will occur (Thai Ministry of Tourism and Sports, 2017). The $2^{\text {nd }}$ National Tourism Development Plan (the Year 2017-2021) emphasizes the distribution of tourism development in local communities and growth based on Thai (Thai Ministry of Tourism and Sports, 2017). In the development strategy, all parties in the tourism network, including government, private and community, are encouraged to participate in management based on sustainable development in terms of identity, lifestyle, culture, tradition, and environment at the level of the area (Thai Ministry of Tourism and Sports, 2017).

At the same time, the development strategy No.3 in the development of tourism personnel and supports the participation of people in tourism development mentioned the promotion of people to participate in tourism management and benefit from tourism. By encouraging people to have knowledge and understanding of tourism and tourism management services, allowing people and communities to participate in the development of basic products and services and local culture. Driving such a development plan into practice requires cooperation from all sectors. In order to make the tourism development plan of the country to be participatory and effective (Thai Ministry of Tourism and Sports, 2017).

The community is an agency in the area of tourism that is living in the tourism area and directly affected by tourism development. Therefore, agencies involved in tourism development should encourage people and communities to participate in the development of national tourism in the appropriate context. Especially in accordance with the local way of life of the community participation in the community and the public sector network will help to increase the identity and Thai identity for tourism and to distribute income from tourism to the public truly.

The participation of communities and people is an important goal of tourism development because people are the owners of the community area with love and cherish the living space. Therefore, relevant agencies must ensure that community members are informed about the development process, opportunities to participate, and the positive and negative effects that will affect 
their life (Ming Ming Su \& Wall, 2014). However, with different objectives, roles and powers in different tourism development, different stakeholders may have different forms of participation and may conflict with each other.

This research selected the study area as the Old Town, Songkhla province, Thailand, with its rich cultural and natural heritage resources. The government is encouraging the Old Town of Songkhla to be a cultural heritage and pushing the Old Town of Songkhla is a world heritage city in the near future. Therefore, the community must develop themselves to be the center of linkage between agencies related to tourism, both in government, private sector to participate in the maintenance and management of natural resources and the environment to be complete in parallel with the growth of tourist attractions. Therefore, researchers are interested in studying community participation for tourism support in order to use the information for improvement and development for the benefit of the community throughout. In addition, the information will be useful to those involved in tourism development management as a way to further develop tourism.

\section{Literature Review}

\section{Residents' perceptions and community participation}

Successful tourism planning based on the support and participation of local people. Understanding residents' perceptions and the response are fundamental to the successful and sustainable development of tourism (Sharpley Richard, 2014). Recognition of the impact of tourism on the community is an indicator of the country's tourism development support and the possibility of developing and managing sustainable development (Jaafar, Noor, \& Rasoolimanesh, 2015; Nicholas Lorraine Nadia, Thapa Brijesh, \& Ko Yong Jae, 2009). Supporting the development of tourist sites of the community depends on the awareness of the positive and negative effects of tourism (Telfer \& Sharpley, 2008).Recognition of positive impacts, encouraging communities to support tourism development,

while the perception of negative effects will keep them away from tourism development (Sharpley Richard, 2014). The awareness of the positive and negative effects of tourism development has an impact on community participation in supporting tourism and the sustainability of tourism development (Nicholas Lorraine Nadia et al., 2009). Therefore, it is important to understand how the community recognizes tourism in order to determine what they need to do in order to receive community support for strategic initiatives related to tourism (Harrill Rich, 2004). Accordingly, the first two research hypotheses are:

H1 Residents' positive perceptions impact on community participation.

H2 Residents' negative perceptions impact on community participation.

\section{Community participation and support for tourism management}

Participation in the tourism development process can help encourage people in the area to be aware of the benefits and costs arising from tourism, which will influence the cooperation to support tourism. Local community participation helps residents play a role in controlling the activities that occur in that community, which may affect their livelihoods from tourism activities (Thongma, Leelapattana \& Hung, 2011). Participation in the decision-making process is beneficial to the local community and encourages people in the community to respect their style of living and their original values (Lindberg \& Johnson, 1997). Several studies indicate that community participation is an important part of sustainable tourism development (Bonimy Madlyn M, 2008; Jamal Tazim B. \& Donald, 1995; Nicholas Lorraine Nadia et al., 2009). In the study of Bonimy Madlyn M (2008) stated that one way to get support from the local community for tourism is to allow the community to participate in the decision-making process. Therefore, this study assumes that community participation has a positive effect on tourism development support. 
H3 Community participation positively impacts on support for tourism development.

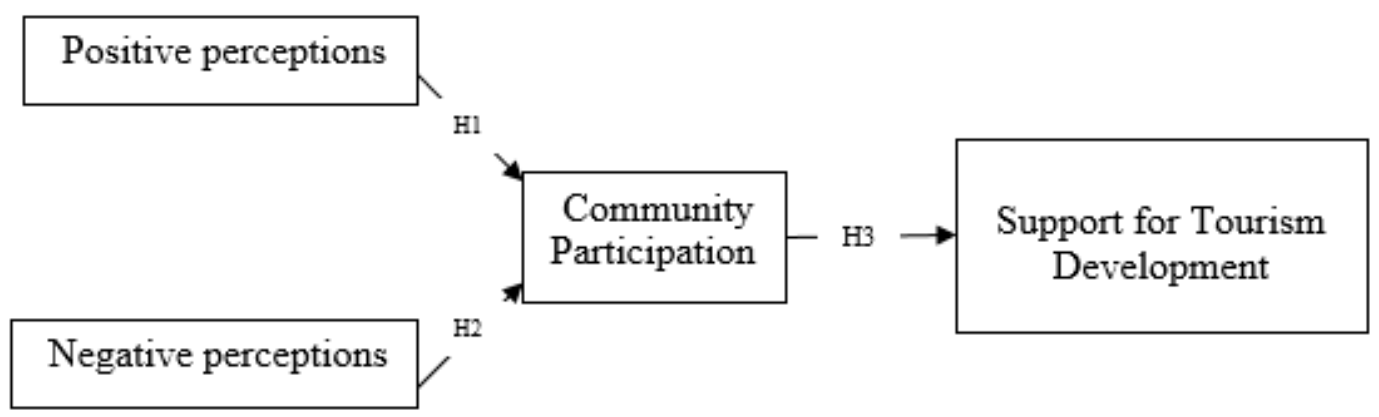

Figure 1. Conceptual Model

\section{Methodology}

\section{Study site}

Songkhla Old Town or Nang Ngam Road located in the Songkhla Municipality area, Bo Yang Sub district, Mueang Songkhla District, Songkhla province. Songkhla Old Town is a historical town with many Chinese. The buildings span an era of around 100 years and reflect various styles. Some buildings have the old British-colonial five-foot-way while some do not. The mix of different styles makes Songkhla Old Town a little different from others in the region, and well worth a visit for the tourists.

\section{Samples and data collection procedure}

A self-administered questionnaire was applied in this research. The research approached the resident at the Songkhla Old Town, Muang Songkhla, Thailand. The required sample size for this research relied on the number of the studied variables and statistical technique being used (i.e., factor analysis) (Hair Joseph F, Black William C, Babin Barry J, \& Anderson Rolph E, 2010), the minimum requirement for sample size is to have at least five participants per variable/ item. Since we were not able to obtain the list of the total population in the suggested area, thereby a non-probability systematic random sampling approach is employed whereby only residents at the Old Town Songkhla. Partial Least Squares Structural Equation Modeling (PLS-SEM) was applied for current research. The total number of completed questionnaires was 222 that are enough for hypothesis testing with a population of more than one million. Would generally be seen as adequate for PLS-SEM (Reinartz Werner, Haenlein Michael, \& Henseler Jorg, 2009). The measurement model related to three main variables namely residents' perceptions (positive perceptions, negative perception), community participation, and support for tourism development were tested for reliability and validity. To test the hypotheses, the structural model was employed.

\section{Measuring instrument}

The questionnaire consists of four main sections. The first section included two sub-constructs underlying residents' perception namely positive perceptions (Gursoy Dogan, Jurowski Claudia, \& Uysal Muzaffer, 2002; Nunkoo \& Ramkissoon, 2011) and negative perception (Gursoy Dogan et al., 2002; Nunkoo \& Ramkissoon, 2011). The second part included four sub-constructs underlying community participation as the second-order construct. The sub-constructs namely decision making, implementation, benefits, and evaluation (Cohen John M \& Uphoff Norman, 1977). The third part is support for tourism development construct (Rasoolimanesh S. Mostafa \& Jaafar Mastura, 2017; Wang Yasong \& Pfister Robert E, 2008). The last section gathers demographic information on the 
respondents such as gender, age, race, education level, and etc. Respondents rated all measures on a five-point Likert-scale, where possible answers ranged from strongly disagree (1) to strongly agree (5).Support for tourism development which measures on a seven-point Likert-type scale, where possible answers ranged from strongly disagree (1) to strongly agree (7)

Table 1. Profile of residents

\begin{tabular}{|l|l|r|r|}
\hline Profile & & Frequency & Percentage \\
\hline \multirow{3}{*}{ Gender } & Male & 91 & 41.00 \\
& Female & 131 & 59.00 \\
\hline \multirow{5}{*}{ Age } & Less than 20 years & 10 & 4.50 \\
& 20-35 years & 62 & 27.90 \\
& 36-50 years & 83 & 37.40 \\
& More than 50 Years & 67 & 30.20 \\
\hline \multirow{5}{*}{ Occupation } & Government employee & 43 & 19.40 \\
& Private company & 16 & 7.20 \\
& Own business & 91 & 41.00 \\
& Student & 18 & 8.10 \\
& Farmer & 1 & 0.50 \\
& Freelance & 30 & 13.50 \\
& Housewife & 18 & 8.10 \\
& Others & 5 & 2.30 \\
\hline \multirow{5}{*}{ Level of Education } & Primary school & 22 & 9.90 \\
Period of Stay in Old & Secondary school & 81 & 36.50 \\
& Bachelor degree & 103 & 46.40 \\
& Above bachelor degree & 8 & 3.60 \\
& Other & 8 & 3.60 \\
\hline \multirow{5}{*}{ Level of Income } & Less than 10,000 Baht & 57 & 25.70 \\
& 10,000-20,000 Baht & 88 & 39.60 \\
& 20,001-30,000 Baht & 48 & 21.60 \\
& More than 30,000 Baht & 29 & 13.10 \\
\hline & Less than 1 year & 11 & 5.00 \\
& 6-10 years & 23 & 10.40 \\
& More than 10 years & 152 & 16.20 \\
& & & 68.50 \\
\hline
\end{tabular}

\section{The sample profile}

The majority of the residents were female (59\%), whereas male accounted for $41 \%$ of the respondents. Thirty percent of the respondents belonged to the 36-50 age groups, other groups are more than 50 $(30 \%)$ and 20-35 (247\%). Forty percent of the residents have their own business. Majority of them hold a bachelor degree $(46.40 \%)$. Eighty- eight respondents were in the income groups between 10,000-20,000 Baht accounting for 39.60\%. Most of the respondents live in the Old Town for more than 10 years $(68.50 \%)$. 


\section{Results and Discussion}

\section{Measurement Model Assessment}

Current research analyzed the data using partial least squares (PLS). To test reliability and validity, PLS algorithms were employed, where appreciate, to test the results of the measure that were determined by groups of variables. This study includes three exogenous variables and one endogenous variable, which all are reflective measurement. Reflective measurement model assessment in the PLS is required composite reliability (CR) to evaluate internal consistency among the indicator for each construct, loading, and average extracted variance (AVE) to assess convergent validity. It also involves cross-loading and Fornell-Larcker criterion to evaluate discriminant validity among constructs of the research model of the study (Mathwick Charla, Malhotra Naresh, \& Rigdon Edward, 2001; Sweeney Jillian C \& Soutar Geoffrey N, 2001).

Table 2. Results of factor loading and reliability analysis.

\begin{tabular}{|l|l|l|l|l|}
\hline Construct & Item & Factor Loading & **AVE & *CR \\
\hline \multirow{5}{*}{ Positive Perceptions } & PP1 & 0.79 & 0.74 & 0.92 \\
\cline { 2 - 5 } & PP2 & 0.88 & & \\
\cline { 2 - 5 } & PP3 & 0.91 & & \\
\cline { 2 - 5 } Negative Perceptions & PP4 & 0.85 & & \\
\hline \multirow{5}{*}{ Community Participation } & NP3 & 0.90 & 0.73 & 0.73 \\
\hline & NP4 & 0.81 & & \\
\hline & Decision & 0.91 & 0.81 & 0.94 \\
\hline & Benefit & 0.88 & & \\
\cline { 2 - 5 } & Practice & 0.90 & & \\
\cline { 2 - 5 } & Evaluation & 0.90 & & \\
\hline & SUP1 & 0.94 & 0.88 & \\
\hline & SUP2 & 0.96 & & \\
\cline { 2 - 5 } & SUP3 & 0.94 & & \\
\cline { 2 - 5 } & SUP4 & 0.90 & & \\
\hline
\end{tabular}

Note: ${ }^{*} \mathrm{CR}=$ composite reliability; $* * \mathrm{AVE}=$ average variance extracted

Table 1 shows the loading, composite reliability (CR), and average variance extracted (AVE). The results show that 14 of the items had the main loading of above 0.708 and AVE was more than 0.5. This result confirms internal consistency among the items for all constructs. Convergent validity assessment builds on the AVE values as the evaluation criterion. The results show that all constructs have AVE above 0.50 (Chin Wynne W, 2010; Hair Joseph F, Hult Tomas, Ringle Christian M, \& Sarstedt Maeko, 2017), which mean AVE, were satisfactory in terms of convergent validity. Therefore, internal consistency and convergent validity of all measurement models are confirmed.

Table 2. Results of descriptive statistic and correlation

\begin{tabular}{|l|l|l|l|l|l|l|}
\hline Construct & Mean & S.D. & CP & NP & PP & SUP \\
\hline Community Participation (CP) & 2.39 & 0.89 & $\mathbf{0 . 9 0}$ & & & \\
\hline Negative Perceptions (NP) & 2.69 & 0.92 & 0.47 & $\mathbf{0 . 8 5}$ & & \\
\hline Positive Perceptions (PP) & 3.86 & 0.82 & 0.45 & 0.07 & $\mathbf{0 . 8 6}$ & \\
\hline Support for Tourism Development (SUP) & 5.69 & 1.51 & 0.43 & 0.07 & 0.58 & $\mathbf{0 . 9 4}$ \\
\hline
\end{tabular}

To test the discriminant validity, the diagonal elements were computed using the square root of AVE. The results of the correlation analysis showed the significant $(p<0.01)$ in each correlation and all of the diagonal elements were larger than their corresponding correlation coefficients. Therefore, the discriminant validity of this study was acceptable (Fornell Clases \& Larcker David F, 1981). Thus, 
this study did not suffer any multicollinearity problem. All the scales met the requirements for testing the structural model. The detail shows in table 2.

\section{Structural Model Assessment}

\section{Finding and Discussion}

The structural model analysis was employed to test the hypotheses. The results of the structural models are provided in Table 3. According to Table 3, from three hypotheses drawn on the relationship between positive perceptions, negative perceptions and community participation, and community participation and support for tourism management all of the hypotheses had found to be significant. Positive perceptions had a positive significant impact on community participation ( $\beta=$ $0.42, \mathrm{p}=0.01)$. It shows that the residents with a positive perception of tourism tend to be involved in tourism development (supporting H1). Then, this study found that negative perceptions had a positive significant impact on community participation $(\beta=0.44, \mathrm{p}=0.01)$ (supporting $\mathrm{H} 2)$. Lastly, the study also found that community participation is positively significant related to support for tourism development $(\beta=0.43, p=0.01)$. Thus, the result supports $\mathrm{H} 3$.

Table 3. Hypothesis testing

\begin{tabular}{|l|l|l|l|l|l|}
\hline Hypothesis & Relationship & Beta & SE & t value & Decision \\
\hline H1 & PP $>$ CP & 0.42 & 0.05 & $8.62 * * *$ & Support \\
\hline H2 & NP $>$ CP & 0.44 & 0.05 & $8.09 * * *$ & Support \\
\hline H3 & CP $>$ SUP & 0.43 & 0.05 & $9.30 * * *$ & Support \\
\hline Note: $* p<0.1, * * p<0.05, * * * p<0.01$
\end{tabular}

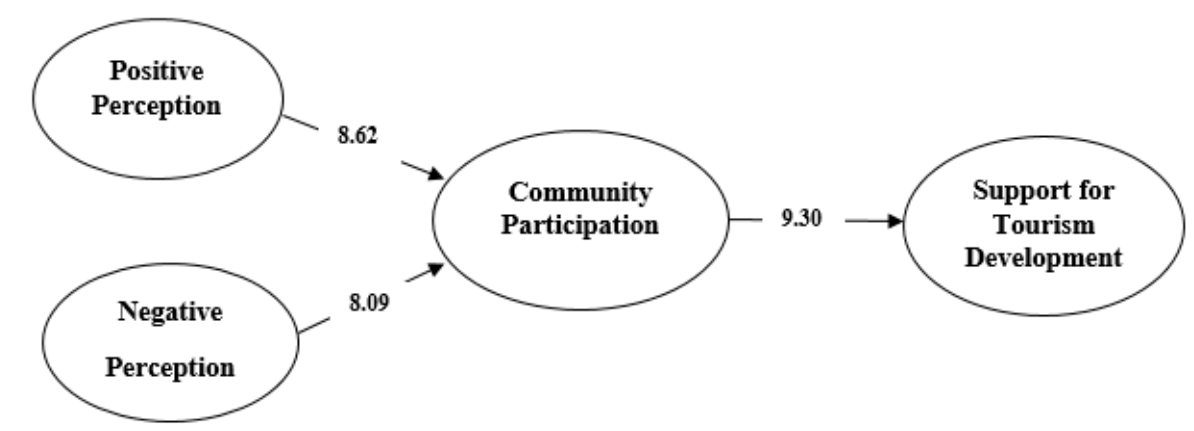

Figure 2. A Structural Equation Model Test

The determinant of support for tourism development in Old Town, Songkhla was investigated from the residents' perceptions (positive and negative) and community participation. For the direct relationship between residents' perceptions and community participation, the results of this study show that both positive and negative perception is an influence on community participation. The finding reveals that positive perception has a significant and positive effect on communication participation. The results are consistent with the previous study by Eshliki Sajad Alipour and Kaboudi Mahdi (2012), who posited that positive perception of the residents is increasing community participation. Meanwhile, the effect of negative perception on community participation is significant 
and positive. This finding is not in line with most of the prior studies in an urban area. The study found that residents'negative perception still tends to participate and support tourism development. These residents are aware of the negative impact of the community on tourism but willing to support and participate in tourism activities. Which may be speculated that the residents who continue to support tourism due to perceived positive effects rather than negative impacts in their community. Second, this study found that community participation had a positive significant impact on support for tourism development which is in line with Kepe Thembela, Saruchera Munyaradzi, and Whande Webster (2004) who mentioned that community participation is an important factor that will benefit the community from tourism development.

\section{Conclusions}

This section provides a conclusion based on the major results of the study. The study is aimed to further enhance the understanding of the impact of residents' perception (positive and negative) on community participation, and community participation on support for tourism development in the Old Town Songkhla, Thailand. The findings hold both theoretical and practical implication. In terms of theoretical contribution, this study conceptualized the model of residents' perceptions, community participation, and support for tourism development among Thai residents to grasp a deeper understanding of the factors that influence residents to support for tourism development in Thailand. For practical contribution, this study provides interesting suggestions for tourism. First, residents' positive perception of the impacts of tourism is the most important predictor of community participation in tourism development. Residents who have a positive perception of the impacts of tourism highly tend to participate in tourism management. The positive impacts of tourism in their perception include create more jobs, attract more investment, improved standards of living and so on. Meanwhile, residents perceive the negative impacts of tourism cause lower participation from any future involvement in tourism development. The community has a view on negative impacts of tourism both economically and socially, such as an increase the cost of living, a rise in the price of property, goods, and other products, increase the rate of crime, pollution, noise, and etc. Thus, it is necessary to provide effective communication between tourism agencies (planners) and community in order to gain community participant and support for tourism development. Second, the results show that community participation effects support for tourism development. Thus, the outcomes of this study have important implications for tourism agencies to ensure that community members are informed of the development process, the chance to participate in all activities and positive and negative impacts to their lives in order to gain support from society (Timothy Dallen \& Tosun Cevat, 2003). Then, they will better participate in community activities as well as support tourism and community development (Bramwell Bill \& Lane Bernard, 1999). Overall, these findings are favorable for tourism-related stakeholders in developing future tourism plans for the area in that residents' appear to be more willing to support tourism development.

However, some limitation in this study should not be overlooked. The first limitation of this study is that the sample of participants might be an accurate reflection of Thai residents in Songkhla Old Town, it is not representative of the general residents in Thailand. Second, this study can be further expanded the factors affected community participation by use of additional variables with respect to institutional arrangements and different stage of tourism development.

\section{Acknowledgments}

The authors would like to thank Faculty of Economics and Business Administration, Thaksin University for funding this research under the Research University grant no. 1/2562. 


\section{References}

Bonimy Madlyn M. (2008). Residents'attitudes and perceptions towards the impact of tourism on the environment in Pigeon Forge, Tennessee. Tennessee State University. Retrieved from https://digitalscholarship.tnstate.edu/dissertations/AAI3307300/

Bramwell Bill, \& Lane Bernard. (1999). Collaboration and partnerships for sustainable tourism. Journal of Sustainable Tourism, 7, 179-181.

Chin Wynne W. (2010). How to write up and report PLS analyses. In V. Vinzi, W. Chin, J. Henseler, \& H.Wang (Eds.), Handbook of partial least squares: Conceps, methods and applications. Heidelberg, Germany: Springer.

Cohen John M, \& Uphoff Norman. (1977). Rural development participation : Concepts and measures for project design, Implementation and evaluation

Eshliki Sajad Alipour, \& Kaboudi Mahdi. (2012). Community perceptiom of tourism impacts and their participation in tourism planning : A case study of Ramsar, Iran. Prodedia Social and Behavioral Sciences, 36, 333-341.

Fornell Clases, \& Larcker David F. (1981). Evaluating structural equation models with unobservable variables and measurement error. Journal of Marketing Research, 18(1), 39-50.

Gursoy Dogan, Jurowski Claudia, \& Uysal Muzaffer. (2002). Resident attitudes: A structural modeling approach. Annals of Tourism Research, 29(1), 79-105.

Hair Joseph F, Black William C, Babin Barry J, \& Anderson Rolph E. (2010). Multivariate data analysis (7th ed.). New Jersey: Pearson Prentice Hall.

Hair Joseph F, Hult Tomas, Ringle Christian M, \& Sarstedt Maeko. (2017). A primer on partial least squares structural equations modeling (PLS-SEM) (2nd ed.). Los Angeles, CA: SAGE.

Harrill Rich. (2004). Residents'attitudes toward tourism development : A literature review with implications for tourism planning. Journal of Planning Literature, 18(3), 251.

Jaafar, M., Noor, S., \& Rasoolimanesh, S. (2015). Perception of young local redents toward sustainable conservation programmes: A case study of the Lenggong world cultural heritage site. Tourism Management, 48, 154-163.

Jamal Tazim B., \& Donald, Getz. (1995). Collaboration theory and community tourism planning Annals of Tourism Research, 22(1), 186-204.

Kepe Thembela, Saruchera Munyaradzi, \& Whande Webster. (2004). Poverty alleviation and biodiversity conservation : a South African Perspective, Oryx. The International Journal of Conservation, 38(2), 143-145.

Mathwick Charla, Malhotra Naresh, \& Rigdon Edward. (2001). Experiential value: conceptualization, measurement and application in the catalog and Internet shopping environment. Journal of Retailing, 77, 39-56.

Ming Ming Su, \& Wall, Geoffrey. (2014). Community participation in tourism at a world heritage site : Mutianyu great wall, Beijing, China. International Journal of Tourism Research, 16, 146-156.

Nicholas Lorraine Nadia, Thapa Brijesh, \& Ko Yong Jae. (2009). Residents' perspectives of a world heritage site: The Pitons Management Area, St. Lucia. Annals of Tourism Research, 36(3), 390-412.

Nunkoo, R., \& Ramkissoon, H. . (2011). Residents' satisfaction with community attributes and support for tourism. Journal of Hospitality \& Tourism Research, 35(2), 171-190.

Rasoolimanesh S. Mostafa, \& Jaafar Mastura. (2017). Sustainable tourism development and residents'perceptions in World Heritage Site destinations. Asia Pacific Journal of Tourism Research, 22, 34-48.

Reinartz Werner, Haenlein Michael, \& Henseler Jorg. (2009). An empirical comparison of the efficacy of covariancebased and variance-based SEM. International Journal of Research in Marketing, 26(4), 332-344.

Sharpley Richard. (2014). Host perception of tourism: A review of the research. Tourism Management, 42, $37-49$.

Sweeney Jillian C, \& Soutar Geoffrey N. (2001). Consumer perceived value: The development of a multiple item scale. Journal of Retailing, 77, 203-220.

Telfer, D., \& Sharpley, R. . (2008). Tourism and development in the development world. London, England: Routledge.

Thai Ministry of Tourism and Sports. (2017). The National Tourism Development Plan (the Year 2017-2021). Bangkok, Thailand: Thai Ministry of Tourism and Sports Retrieved from https://www.mots.go.th/more_news.php?cid=312\&filename=index.

Timothy Dallen, \& Tosun Cevat. (2003). Appropriate planning for tourism in destination communities: participation, incremental growth and collaborationIn. Tourism in Destination Communities, Singh S, Timothy DJ, Dowling RK (eds). Wallingford, UK: CABI Publishing.

Wang Yasong, \& Pfister Robert E. (2008). Residents' attitudes toward tourism and perceived personal benefits in a rural community. Journal of Travel Research, 47(1), 84-93. 